\title{
ДИСКУССИИ
}

DOI: https://doi.org/10.15688/jvolsu2.2018.3.22

UDC 81'373.612.2

Submitted: 01.06.2018

LBC 81.055 .51

Accepted: 28.06.2018

\section{POETIC METONYMY AS A TYPE OF LEXICAL MEANING AND ITS REFLECTION IN LEXICOGRAPHIC PRACTICE}

\author{
Arkadiy L. Golovanevskiy \\ Bryansk State University named alter Academician I.G. Petrovsky, Bryansk, Russia
}

\begin{abstract}
The paper develops the theory of metonymy in the Russian language, and for the first time in Russian linguistics it is proposed to distinguish the actual and event metonymy. The actual metonymy is represented in figurative meanings of nouns that denote parts of the human body (hand, head, etc.), constructions (house, auditorium, etc.), clothes (hat, boots), metals, various containers, etc. Secondary values of place names, names of various artifacts are interpreted as event metonymy. Event metonymy is necessarily inextricably linked with time, optionally - with topos. Observations on the use of metonymy are carried out on the material of poetic works by A. S. Pushkin, F. I. Tyutchev, A. Blok, S. Esenin, E. G. Bagritsky. It is established that in the poetic texts of the twentieth century the event metonymy is used more frequently than in the works of the nineteenth century, for instance, it is represented in the poem Retribution by A. Blok. It is revealed that the meanings of lexical units as a result of event metonymy have not been recorded in the explanatory dictionaries of the Russian language, with one exception - the third edition of the dictionary of Dahl that was carried out by I. A. Baudouin de Courtenay. The conclusion is made about the necessity of lexicographical fixation of such words due to their highly informational and stylistic significance.
\end{abstract}

Key words: metonymy, metaphor, poetic text, Pushkin, Tyutchev, Blok, Esenin, Bagritsky.

Citation. Golovanevskiy A.L. Poetic Metonymy As a Type of Lexical Meaning and Its Reflection in Lexicographic Practice. Vestnik Volgogradskogo gosudarstvennogo universiteta. Seriya 2, Yazykoznanie [Science Journal of Volgograd State University. Linguistics], 2018, vol. 17, no. 3, pp. 203-209. (in Russian). DOI: https:// doi.org/10.15688/jvolsu2.2018.3.22

\section{ПОЭТИЧЕСКАЯ МЕТОНИМИЯ КАК ТИП ЛЕКСИЧЕСКОГО ЗНАЧЕНИЯ И ЕЕ ОТРАЖЕНИЕ В ЛЕКСИКОГРАФИЧЕСКОЙ ПРАКТИКЕ}

Аркадий Леонидович Голованевский

Брянский государственный университет имени академика И.Г. Петровского, г. Брянск, Россия

Аннотация. В статье развивается учение о метонимии в русском языке и впервые в отечественной лингвистике предлагается выделять такие ее разновидности, как фактическая и событийная. Первая из них представлена в переносных значениях конкретных существительных, номинирующих части человеческого тела (рука, голова и др.), сооружения (дом, аудитория и т. п.), одежду (шляпа, сапоги), металлы, различные вместилища и многое другое. Как событийная метонимия интерпретируются вторичные значения топонимов, названия различных артефактов. Эта разновидность обязательно связана со временем, факультативно - 
с топосом. Наблюдения над употреблением метонимии осуществлены на материале поэтических произведений А.С. Пушкина, Ф.И. Тютчева, А.А. Блока, С.А. Есенина, Э.Г. Багрицкого. Установлено, что в поэтических текстах XX в. событийная метонимия реализовалась чаще, чем в произведениях XIX в. Особенно широко она представлена в поэме А.А. Блока «Возмездие». Выявлено, что значения лексических единиц, возникающие как результат событийной метонимии, не фиксируются в толковых словарях русского языка, исключение составляет третье издание словаря В.И. Даля, осуществленное И.А. Бодуэном де Куртенэ. Делается вывод о необходимости лексикографической фиксации таких слов в силу их высокой информационной и стилистической значимости.

Ключевые слова: метонимия, метафора, поэтический текст, Пушкин, Тютчев, Блок, Есенин, Багрицкий.

Цитирование. Голованевский А. Л. Поэтическая метонимия как тип лексического значения и ее отражение в лексикографической практике // Вестник Волгоградского государственного университета. Серия 2, Языкознание. -2018. - Т. 17, № 3. - С. 203-209. - DOI: https://doi.org/10.15688/jvolsu2.2018.3.22

\section{Дискуссионные вопросы изучения метонимии \\ в отечественном языкознании}

Изучение метонимии как одного из типов переносного значения слова связано с целым рядом проблем. Некоторые из них обозначил Д.Н. Шмелев в монографии «Проблемы семантического анализа лексики». Во-первых, он считал, что употребление термина «метонимия» двупланово: собственно лингвистическое и стилистическое. Это приводит зачастую к смешению понятий «значение» и «употребление». Во-вторых, он отмечал необходимость разграничения маркировки метонимических значений и общей возможности их применения. В-третьих, выдвигал требование унифицировать представление в толковых словарях метонимических значений на основе разрешения первых двух обозначенных проблем [Шмелев, 1973, с. 221-228].

В учебном пособии по лексикологии Д.Н. Шмелев несколько снизил дискуссионность в понимании метонимических значений и привел довольно объемный и открытый перечень различных типов метонимических переносов, не отказавшись в то же время от основных идей о понимании метонимии, изложенных ранее в научной монографии [Шмелев, 1977, с. 97-101].

В названной монографии исследователь подвергает сомнению взгляды Л.А. Булаховского на приводимые им примеры «метонимических изменений значений». К таким изменениям Л.А. Булаховский относил и синекдоху: И сльшино было до рассвета, как ликовал француз. Метонимические явления широко распространены в языке и, по наблю- дениям Д.Н. Шмелева, «воспринимаются как специальный стилистический прием» [Шмелев, 1977, с. 223]. Именно на этом основании А.П. Квятковский определяет метонимию как «распространенный поэтический троп, замена слова или понятия другим словом, имеющим причинную связь с первым» [Квятковский, 1966, с. 158-159]. Включение стилистического приема в метонимические изменения создает условия для широкого понимания метонимии, отвергаемое Д.Н. Шмелевым.

Бесспорно, прав Д.Н. Шмелев, заявляя: «Конечно, не с точки зрения метонимических изменений, а только как метонимическое применение слов можно рассматривать и случаи вроде читал Пушкина, слушал Бетховена и т. д.» [Шмелев, 1977, с. 106]. Это явление в языке обусловлено принципом экономии, и поэтому каждое имя автора (а их множество) не может приобрести индивидуального метонимического значения, но может свободно использоваться в формульном метонимическом употреблении. Этой формуле подчиняются и широко известные, и мало известные имена. Например: Mbl puфмы старые Раз сорок повторим. Пускать сумеем Гоголя и дым (Есенин, с. 269); Настал наш срок, Давай, Сергей, За Маркса тихо сядем, Чтоб разгадать премудрость скучных строк (Есенин, с. 273); Здесь он стоял... Здесь рвался плаш широкий, Здесь Байрона он нараспев читал... (Багрицкий, с. 291); Его опустошает Демон, Над коим Врубель изнемог (Блок, т. 2, с. 309).

Вклад в изучение метонимии внесли многие лингвисты. Ю.Д. Апресян, рассматривая регулярную многозначность существительных, глаголов, прилагательных, приводит 
многочисленные примеры метонимического переноса [Апресян, 1995, с. 193-215], тем самым способствует совершенствованию лексикографической практики. Н.Д. Арутюнова в специальном разделе «Метафора и метонимия» сосредоточила основное внимание на употреблении словосочетаний и предложений с метафорическими и метонимическими компонентами и на функциях, выполняемых в предложении метафорой и метонимией.

В словарях семантика слова, возникающая в результате метонимии, как правило, не получает толкования, что сближает прямое и метонимическое значения лексемы, хотя последнее в любом контексте сохраняет свою переносность и метонимия как тип переносного значения сближается с метафорой. При этом «из двух возможных для метафоры функций первичной должна быть признана функция характеризации, а функция идентификации объектов - вторичной. < ..> Для метонимии, напротив, типично выполнение идентифицирующей функции по отношению к конкретным предметам» [Арутюнова, 1999, с. 352].

Метонимия, в нашем понимании, создает такие значения слов, которые включаются в языковую систему по тем или иным формулам, но при этом, будучи отражением процесса человеческой или природной деятельности, изменяют, трансформируют свою функцию [Голованевский, 2013, с. 176-177], о которой и говорит Н.Д. Арутюнова. Такие типы значений, представляется, должны фиксироваться словарями как переносные.

Поэтический язык породил особый тип метонимии-метафоры, когда происходит одновременно «сдвиг в значении» и «сдвиг в референции». Из этих наблюдений нами сделан вывод о том, что базой для лексической неоднозначности могут служить не только прямые значения, совмещенные с одним из типов переносных, но и сами переносные значения - метонимия и метафора [Голованевский, 2013, с. 178]. Этот вывод подтверждается поэтической практикой. В языке поэзии образные средства не изолированы, а составляют систему, в то время как метонимия встречается в чистом виде довольно редко, чаще она соседствует с метафорой, нередко совмещается с ней в одной лексеме.
В настоящей статье обобщены наблюдения над метонимией в поэтических произведениях А.С. Пушкина, Ф.И. Тютчева, А.А. Блока, С.А. Есенина, Э.Г. Багрицкого. За основу метонимической типологии принята классификация, представленная в работах Д.Н. Шмелева и Н.Д. Арутюновой (полной классификации метонимических переносов до настоящего времени не существует). Проблему лексикографирования метонимических значений рассмотрим на примере трех типов метонимии (два из них традиционно выделяются исследователями и относятся, по нашей классификации, к фактической метонимии; третий тип определен автором статьи как событийная метонимия).

\section{Фактическая метонимия в языке поэзии}

Под фактической метонимией мы понимаем такие метонимические значения отдельных слов, которые номинируют человека, животный и растительный мир, артефакты и другие предметы, под событийной торжества, печальные даты, войны, зрелищные мероприятия и др. (см. подробно: [Голованевский, 2017, с. 65]).

Перенос названия с вместилища (блюдо, бокал, кубок, амфора) на его содержимое: И за столом у них гостям Носили блюды по чинам; Она не ведает, что дружно можно жить С кифарой, с портиком, и с книгой, и с бокалом; Ты Эпикуров младший брат, Душа твоя в бокале (СЯП, т. 1, с. 142-143); Ни ссоры, ни упреку Не нажил за бокал (Тютчев, с. 60-61); Приди - тебя здесь ждет и кубок круговой... (Тютчев, с. 47); Вдруг с кубком не слюбился Один из сыновей (Тютчев, с. 61).

В поэтических произведениях обнаруживается совмещение прямого и метонимического значений лексем. Так, в стихотворении Тютчева «Певец» читаем: $О н$ кубок взял $и$ осушил (Тютчев, с. 90). В этом примере существительное кубок употребляется в прямом значении 'сосуд' (взял кубок) и в метонимическом значении 'содержимое сосуда' (осушил кубок). Таким образом, в метонимическо-метафорическом поле оказываются у Тютчева существительное и глагол. Ни в 
СРЛЯ, ни в СЯП, ни в СОШ метонимическое значение слова кубок не указывается, по-видимому, потому, что вместилище для того и служит, чтобы его наполняли содержимым.

В поэтическом тексте возможно совмещение метонимического и метафорического значений. Так, поэтический кубок, или фиал, наполняется не только вином: ... И в кубок ваш все жарче и светлее Так вдохновение лилось (Тютчев, с. 204-205); здесь кубок поэзия П.А. Вяземского. У Пушкина поэтическое творчество - метонимический поэтический бокал: ... И в поэтический бокал Boды я много подмешал, - пишет он в «Евгении Онегине» (Пушкин, т. 2, с. 343).

В поэтическом тексте возможно также совмещение двух метонимических значений. Так, в названии стихотворения Блока «Сквозь винный хрусталь» (Блок, т. 2, с. 24) одновременно представлены: 1) перенос названия вместилища на его содержимое, 2) перенос названия материала (стекла) на изделие из него.

Перенос названия материала на изделие из него - продуктивный поэтический тип метонимии. Чаще всего в этих значениях выступают существительные, номинирующие различные виды оружия, скульптуры, сооружения. Для Пушкина, Тютчева, Блока характерно употребление в данном метонимическом значении таких лексем, как алмаз, броня, булат, гранит, медь, металл, мрамор, бронза. Например: У русского изаря в чертогах есть палата: Она не золотом, не бархатом богата; не в ней алмаз вениа хранится за стеклом (СЯП, т. 1, с. 35); В горьком опыта фиале Твой алмаз на дне горит. (Тютчев, с. 62-65) (здесь алмаз - 'алмазный перстень'); Янтарь на трубках Цареграда, Фарфор и бронза на столе, И чувств изнеженных отрада, Духи в граненном хрустале (СЯП, т. 4, с. 876); Под грозной броней ты не ведаешь ран (СЯП, т. 1, с. 169); ... И с иелой армией в бронях и на коне Противу мальчиков воюют? (Тютчев, с. 282); И, задрожав, булат холодный Вонзился в дерзостный язык (СЯП, т. 1, с. 179); Снова ль, Гектор, мчишься в поле брани, Где с булатом в неприступной длани. Мстительный свирепствует Пелид? (Тютчев, c. 59-60); С душою, полной сожалений, $и$ опериися на гранит, Стоял задумчиво Ев- гений (СЯП, т. 1, с. 547); Стояла тыл, младая фея, На миистый опершись гранит ... (Тютчев, с. 136-137) (здесь гранит - 'развалины гранитных стен замка'); Но эти милье забавы Не затемнили образ твой, И в бронзе выкованной славы Трясешь ты гордой головой (Есенин, с. 244); Но, обреченный на гоненье, Еще я долго буду петь ... Чтоб и мое степное пенье Сумело бронзой прозвенеть (Есенин, с. 245); В струнах ли мечтаешь укрыться златьхт? Металл содрогнулся, тобой оживлен (Тютчев, с. 78); Металла голос погребальный порой оплакивает нас (Тютчев, с. 80).

Как метонимические в сочетаниях с существительными могут выступать прилагательные, например, у Тютчева: И звоном меди православной все огласились высоmы (Тютчев, с. 254). Медь православная 'колокола православных церквей'. В стихотворении «17-е апреля 1818», в день 55-летия императора Александра II, поэт вспоминает: На первой дней моих заре ... Я в келье был, И тихой и смиренной, Там жил тогда Жуковский незабвенный. Я ждал его, и в ожиданье ... Следил за медной бурей, поднявшейся в безоблачном лазуре И вдруг смененной пушечной пальбой (Тютчев, с. 276). Метонимически-метафорическое словосочетание медная буря в значении 'частый и сильный колокольный звон' базируется на метонимической семантике существительного медb и метафоре бури.

Метафоро-метонимическое сочетание существительного и прилагательного использует и Блок, например, в стихотворении «Пожар»: Впереди скакун с трубой Над испуганной толпой. Скок по камню тяжско звонок. Голос хриплой меди тонок (Блок, т. 1, с. 304).

Как видно из приведенных поэтических строк, метонимический перенос усиливает образность стиха, сочетаясь с метафорой (прилагательным, глаголом, существительным), и таким образом создается обогащенное образное поэтическое поле.

Этот тип метонимического значения в словарях отражается непоследовательно. В СОШ приводятся метонимические значения (без указания на их образность) лексем: хрусталь - 2. 'Посуда и другие изделия из этого стекла' (СОШ, с. 870); бронза - 2. 'Художе- 
ственное изделие из такого сплава' (СОШ, c. 60); булат - 2. 'Стальной клинок, меч' (СОШ, с. 63); золото - 2. 'Монеты или изделия из этого металла' (СОШ, с. 232) и некоторых других. При этом они не отмечаются у лексем алмаз, янтарь, медь и многих других. Мы считаем, что в авторской лексикографии эти метонимические значения должны быть зафиксированы, возможно, и без указания на их переносность. Такой подход, позволяющий отразить особенности употребления лексем гранит, медный, алмаз и других, реализован в «Поэтическом словаре Ф.И. Тютчева» (Голованевский, 2009).

\section{Событийная метонимия в языке поэзии}

Весьма распространенной в поэзии является оценочная характеристика события, отраженная в событийной метонимии, когда само событие не называется, а как бы шифруется указанием на время, в которое оно происходило, упоминанием его участников, топонимов, связанных с важными моментами данного события и другими факторами, имеющими непосредственное отношение к описываемым событиям. Как правило, в языке художественной литературы такой метонимический прием используется по «горячим следам» прошедших событий, поэтому он не вызывает затруднений в «расшифровке» темпоральных лексем, топонимов или антропонимов. При этом со временем, если эти номинации не закрепились в литературном языке в качестве словарных дефиниций в толковых словарях или не сохранились в памяти народа, то необходимы дополнительные разъяснения для точного понимания называемых дат и имен. Обратимся к поэтическим контекстам:

Снежные Балканы, Три Плевны, Шипка и Дубняк, Незаживающие раны, И хитрый и неслабый враг ... (Блок, т. 2, с. 279); Раскинулась необозримо Уже кровавая заря, Грозя Артуром и Цусимой, Грозя Девятым января (Блок, т. 2, с. 301); Как тяжкий бык, копытом бьющий травы, Крутоголовый, полный страшных сил, Здесь пятый год, великий и кровавый, Чудовищную ношу протащил (Багрицкий, с. 289); Отдам всю душу октябрю и маю, Но только лирь милой не отдам (Есенин, с. 251). Прочтешь не в буквах, а в другом, Что в той стране, где власть Советов, Не пишут старым языком. ... Лишь потому так неумело шептал бумаге карандаш (Есенин, с. 252).

Из названных здесь имен и дат в словари различных типов вошли Шипка, Октябрь, май. И.А. Бодуэн де Куртенэ в третьем издании словаря В.И. Даля сопроводил словарную статью «Шипка» такой иллюстрацией: «На Шипке все спокойно... Эти слова вошли в поговорку для обозначения, что мнимо все хорошо, а на самом деле скверно» (Даль, т. 3, c. 1436). Октябрь - 2. 'Великая Октябрьская социалистическая революция’ (СРЛЯ, т. 8, c. 829-830). Май- Перен. 'О счастливой поре жизни и молодости’ (СРЛЯ, т. 6, с. 499). Отметим, что результаты событийной метонимии имен собственных входят в лексическую систему языка, например, Ватерлоо, Седан стали нарицательным именами и служат для 'обозначения поражений, крушения завоевательной политики, старого режима какоголибо государства' (Голованевский, 1995, с. 23, 95). Такими именами стали Порт-Артур, Цусима и др. Употреблялись они в основном в публицистике, откуда и вошли в поэзию и различные словари.

\section{Выводы}

Учение о метонимии привело нас к пониманию того, что можно выделить два ее типа: фактическую и событийную. Первая из них свойственна переносным значениям конкретных существительных, обозначающих части человеческого тела (рука, голова и т. п.), сооружения (дом, аудитория и т. п.), одежду (шляпа, сапоги), металлы, различные вместилища и много другое.

К событийной метонимии отнесем вторичные значения топонимов, названия различных артефактов. История государств, отдельных городов, артефактов порождает событийную метонимию, обязательно связанную со временем, факультативно - с топосом. Событий вне времени не бывает.

Событийную метонимию широко использовали Блок, Есенин, Багрицкий. У Тютчева названия городов, государств обычно употребляются в фактическом значении с обозначе- 
нием их жителей. В результате употребления слов в метонимических значениях в языке поэзии образуются сложные метафоро-метонимические конструкции, совмещение прямого и переносного значений лексем.

В статье мы кратко рассмотрели лишь три типа метонимических значений, используемых в русской поэзии, в том числе и не выделяемую исследователями событийную метонимию. Понятно, что такими переносами она не ограничивается. Весьма продуктивными типами являются: 'Населенный пункт -жители'; 'Часть - целое' и обратное; 'Человек, животное - артефакт, который используется ими'; 'Учреждение - люди, работающие или находящиеся там' и др. Каждый из этих метонимических типов может стать предметом специального исследования. Только дальнейшее изучение использования метонимии в языке вообще и отдельного автора в частности может способствовать лучшему пониманию природы этого образного средства и возможности его лексикографической маркировки.

\section{СПИСОК ЛИТЕРАТУРЫ}

Апресян Ю. Д., 1995. Лексическая семантика. Синонимические средства языка. М. : «Языки русской культуры». $472 \mathrm{c}$.

Арутюнова Н. Д., 1999. Язык и мир человека. М. : «Языки русской культуры», 1999. $896 \mathrm{c}$.

Голованевский А. Л., 2013. Тютчев - русская языковая поэтическая личность : монография. Брянск : «Курсив». 292 с.

Голованевский А. Л., 2017. Концепт ФАКТ в мире языка // Вопросы когнитивной лингвистики. Вып. 3. С. 63-75.

Квятковский А. П., 1966. Поэтический словарь. М. : «Советская энциклопедия». 375 с.

Шмелев Д. Н., 1973. Проблемы семантического анализа лексики. М. : «Наука». 280 с.

Шмелев Д. Н., 1977. Современный русский язык. Лексика. Учебное пособие для студентов пед. ин-тов по специальности «Рус. яз. и литература». М. : «Просвещение». 335 с.

\section{ИСТОЧНИКИ И СЛОВАРИ}

Багриикий-Багрицкий Э. Г. Стихи и поэмы. М. : «Художественная литература», 1956.335 с.
Блок-Блок А. А. Собрание сочинений : в 6 т. Л. : «Художественная литература», 1980-1983.

Голованевский, 1995 - Голованевский А. Л. Идеологически-оценочный словарь русского языка XIX - начала XX вв. Брянск : Брянский государственный университет, 1995.170 с.

Голованевский, 2009 - Голованевский А. Л. Поэтический словарь Ф.И. Тютчева. Брянск : Брянский государственный университет, 2009.960 c.

Даль - Даль В. И. Толковый словарь русского языка : в 4 т. / под ред. И. А. Бодуэна де Куртенэ. Изд. 3е. СПб. : Тип. Товарищества М.О. Вольф, 1903-1909.

Есенин - Есенин С. А. Стихотворения. Поэмы. М. : «Художественная литература», 1965. $551 \mathrm{c}$.

Пушикин-Пушкин А. С. Сочинения : в 3 т. М. : Худож. лит., 1985-1987.

Тютчев - Тютчев Ф. И. Полное собрание стихотворений. Л., «Советский писатель», 1987. 447 с.

СОШ - Ожегов С. И., Шведова Н. Ю. Толковый словарь русского языка. 4-е изд. с дополн. М. : «Азбуковник», 1997.940 с.

СРЛЯ - Словарь современного русского литературного языка. : в 17 т. М. ; Л. : Изд. АН СССР, 1950-1965.

СЯП - Словарь языка Пушкина : в 4 т. / отв. ред. акад. АН СССР В. В. Виноградов. 2-е изд. доп. М. : «Азбуковник», 2000.

\section{REFERENCES}

Apresyan Yu.D., 1995. Lexical semantics. Synonymic language means. Moscow, Yazyki russkoy kultury Publ. $472 \mathrm{p}$.

Arutyunova N.D., 1999. Language and human world. Moscow, Yazyki russkoy kultury Publ. 896 p.

Golovanevskiy A.L., 2013. Tyutchev as a Russian linguistic poetic identity : monography. Bryansk, Kursiv Publ. 292 p.

Golovanevskiy A.L., 2017. Concept fact in the world of language. Voprosy kognitivnoy lingvistiki [Issues of Cognitive Linguistics], iss. 3, pp. 63-75.

Kvyatkovskiy A.P., 1966. Poetic dictionary. Moscow, Sovetskaya entsiklopediya Publ. $375 \mathrm{p}$.

Shmelev D.N., 1973. Problems of the vocabulary semantic analysis. Moscow, Prosveshchenie Publ. $335 \mathrm{p}$.

Shmelev D.N., 1977. The modern Russian language. Vocabulary. Textbook for students of pedagogical universities specializing in the Russian language and literature. Moscow, Nauka Publ. 335 p. 


\section{SOURCES AND DICTIONARIES}

Bagritskiy E.G., 1956. Verses and poems. Moscow, Khudozhestvennaya literatura Publ. $335 \mathrm{p}$.

Blok A.A. Collected works in 6 vols. Leningrad, Khudozhestvennaya literatura Publ., 1980-1983.

Golovanevskiy A.L., 1995. Ideological axiological dictionary of the Russian language of the 19thearly 20th centuries. Bryansk, Izd-vo BGU. 170 p.

Golovanevskiy A.L., 2009. The poetic dictionary of F.I. Tyutchev. Bryansk, Izd-vo BGU. 960 p.

Dal V.I. Explanatory dictionary of the Great Russian language. In 4 vols. Saint Petersburg, Tip. Tovarishchestva, 1903-1909.
Esenin S.A., 1965. Verses. Poems. Moscow, Khudozhestvennaya literatura Publ. $551 \mathrm{p}$.

Pushkin A.S. Writings : in 3 vols. Moscow, Kzudozh. lit. Publ., 1985-1987.

Tyutchev F.I., 1987. Complete collection of poems. Leningrad, Sovetskiy pisatel Publ. $447 \mathrm{p}$.

Ozhegov S.M., Shvedova N.Yu., 1997. Explanatory dictionary of the Russian language. Moscow, Azbukovnik Publ. $940 \mathrm{p}$.

Dictionary of the modern Russian literary language. In 17 vols. Moscow; Leningrad, Izd-vo AN SSSR, 1950-1965.

Vinogradov V.V., ed., 2000. Pushkin's language dictionary. In 4 vols. Moscow, Azbukovnik Publ.

\section{Information about the Author}

Arkadiy L. Golovanevskiy, Doctor of Sciences (Philology), Professor of Department of the Russian Language, Bryansk State University named after Academician I.G. Petrovsky, Bezhitskaya St., 14, 241036 Bryansk, Russia, golovanevski@mail.ru, https://orcid.org/0000-0002-4023-3138

\section{Информация об авторе}

Аркадий Леонидович Голованевский, доктор филологических наук, профессор кафедры русского языка, Брянский государственный университет им. акад. И.Г. Петровского, ул. Бежицкая, 14, 241036 г. Брянск, Россия, golovanevski@mail.ru, https://orcid.org/0000-0002-4023-3138 